\title{
O SIGNICADO DA ASSISTÊNCIA DE ENFERMAGEM NO RESULTADO DA ASSISTÊNCIA À SAÚDE
}

\author{
Maria Tereza Leopardi* \\ Maria Cecília Puntel de Almeida** \\ Scmiramis Melani Mclo Rocha**
}

\begin{abstract}
RESUMO - Este trabalho foi apresentado no XL CBEn, realizado em Belém, PA, em 1988 , dentro da temática central - o processo de trabalho na enfermagem - com o objetivo de trazer ao debate o significado da assistência de enfermagem no resultado da assistência à saúde. Inicialmente traz uma síntese sobre a conceituação teórica da assistência de enfermagem. A seguir, tomando-se como dados empíricos 16 entrevistas com enfermeiras da cidade de Ribeirão Preto, procura-se verificar se o concreto corresponde às conceituações teóricas, os distanciamentos, caracterizar o processo de trabalho em enfermagem, suas limitações e desenvolvimento, a divisão entre os vários agentes e sua finalidade.
\end{abstract}

\begin{abstract}
This work was presented on the XL CBEn, which was realized in Belem, $P A$, in 1988, around the central thematic - the process of working of the nursing helping in the result of the assistance to health. To start with this work, it brings a synthesis about the theoretic concept in nursing. Next it takes as an empirical date 16 interviews from nurses from Ribeirão Preto, we tried to verify if the real corresponds to the theoretical concepts, if the distances which are, the historical reasons for these distances, to characterize the process of working in nursing, their limitations and development, the division of the various agents and its result.
\end{abstract}

\section{INTRODUÇÃO}

Dizer o óbvio aqui representa esclarecer nossa orientação metodológica e fillosófica, que inclui uma forma peculiar de ver a realidade, uma concepção segundo a qual todos os produtos da vida social são historicamente determinados. Assim, todas as teorias e interpreta ções sobre a situação estudada são vistas em suas limitações e transitoriedade. Procuramos, pois, a relação das idéias e das práticas sociais enquanto proposta para ser discutida, sem pretensões de esgotá-la neste debate.

Nestes últimos cinco anos, os enfemeiros e a $\mathrm{ABEn}$, sua importante entidade de classe, vêm fazendo uma reflexão sobre o próprio trabalho de enfermagem. apontando-o como um processo e identificando os pontos de atrito e conflito que têm sua determinação na própria especificidade do trabalho na enfermagem e na saúde e também enquanto um trabalho social.
Estes questionamentos não são resultados da reflexão teórica dos agentes da enfermagem produzidos isoladamente, mas refletem os conflitos da própria prática.

No último CBEn. ocorrido na Bahia $\mathrm{cm} \mathrm{1987,} \mathrm{a}$ ABEn tomou como tema central o trabalho na enfermagem, através da análise deste processo e da sua divisão técnica; a inserção da cnfermagem no mercado de trabalho e as condições de trabalho.

Neste XL CBEn a ABEn opta novamente por esta temática para a discussão, tentando aprofundar alguns ângulos desta questão que ainda são tangenciais.

Coube a nós trazer para o debate o significado da assistência de enfermagem no resultado da assistência à saúde, abordando os seguintes sub-temas: caracterização da assistência de enfermagem: análise dos determinantes na atual assistência de enfermagem no Brasil e a introdução do debate sobre o papel da

* Professor Adjunto Do Departamento De Enfermagem da UFSC

** Professor Assistente Doutor do Departamento de Enfermagem Materno-Infantil e Saúde Pública da Escola de Enfermagem de Ribeirao Preto - USP. 
assistência no resultado da assistência à saúde.

Neste momento da história brasileira, em que o sctor social vem sendo apontado como meta dos poderes públicos, temos visto como tem sido difícil a sua organização no atendimento das questões básicas de vida, como habitação, transporte, educação, saúde, entre outras.

As políticas de saúde, como parte das políticas sociais, vêm sofrendo grandes transformações, apontando para a reforma sanitária brasileira que se encontra $\mathrm{em}$ processo de andamento, requerendo um esforço conjunto de entidades, trabalhadores da saúde, instituições e população para sua efetiva realização.

Para se falar $\mathrm{cm}$ assistência à saúde é necessário que se fale em assistência de enfermagem.

Temos em mente apontar para alguns conflitos que permeiam o trabalho dos enfermeiros e da enfermagem. Fazemos as seguintes perguntas:

- qual o entendimento dos enfermeiros sobre a assistência de enfermagem. e qual seu papel concreto nesta assistência?

- de que modo se sentem comprometidos individual ou coletivamente com as necessidades de saúde dos brasileiros?

- os enfermeiros percebem a necessidade de discutir a assistência a saúde, c, nesse contexto, discutir a assistência de enfermagem, no contexto nacional?

A forma que pensamos para abordar o tema do significado da assistência de enfermagem e sua caracterização foi, primeiramente, fazer uma sintese sobre a conceituação da assistência no plano formal, através do levantamento de algumas teorias de enfermagem.

A partir desta conceituação teórica passamos para o terceiro momento do trabalho, ou seja, buscar a fala dos próprios agentes da enfermagem sobre o seu trabalho e assim verificarmos as aproximações e distanciamentos com aquela conceituação teórica. Buscamos com os dados empíricos, ou seja, a fala dos enfermeiros, não só verificar se o concreto corresponde às conceituações teóricas e quais as razões históricas dos distanciamentos, mas muito mais. caracterizar o processo de trabalho em enfermagem, suas limitações e os determinantes internos e externos do processo.

Sabemos que, quando falamos em assistência de enfermagem, não estamos falando do trabalho do enfermeiro somente, mas de toda a categoria profissional. Porém, devido ao pouco tempo disponível para a realização do mesmo, optamos por entrevistar so- mente enfermeiros e discorrer sobre o seu trabalho mesmo sabendo que é uma limitação.

A amostra de enfermeiros selecionada para entrevista foi da cidade de Ribeirão Preto, Estado de São Paulo, tendo-se o cuidado de incluir um de cada tipo de instituição de saúde, tanto das particulares como das públicas, assim como das hospitalares e as de saúde pública. Portanto, o número de enfermeiros correspondeu a 16 dentre aqueles que estavam mais ligados à assistência de enfermagem, eliminando-se os que ocupavam cargos de direção. As entrevistas foram realizadas de forma aberta, propondo-se que inicialmente o enfermeiro falasse sobre sua história profissional. A duração das entrevistas girou em torno de 45 minutos a 1 hora. As gravações foram ouvidas, registrando-se as falas em tópicos específicos como: o que é o trabalho do enfermeiro, suas limitações, a visão do enfermeiro sobre a enfermagem e o setor saúde entre outros. Em alguns momentos da discussão do trabalho transcrevemos trechos das falas para maior ilustração.

Outra limitação para este trabalho é que estamos falando da assistência de enfermagem de um municipio da região sudeste do país que provavelmente guarda características próprias que não podem ser gencralizadas para o Brasil em sua totalidade.

\section{CONCEITUAÇÃO DE ASSISTÊNCIA DE ENFERMAGEM}

Tendo como base que o conhecimento, em qualquer área da atividade humana, é um instnumento do real, com maiores ou menores níveis de aproximação, vamos analisar algumas definições de assistência de enfermagem contidas em algumas das teorias de enfermagem.

Sendo que os enfermeiros querem dar à sua atividade um caráter metódico e científico, teorias de enfermagem têm sido propostas, e se tem tentado aplicá-las à prática. No entanto, porque elas não são unicamente métodos, mas são também formas particulares de ver a saúde e o trabalho do enfermeiro, sistematizar a assistência de enfermagem de acordo com teorias não tem tido os resultados esperados. Não apenas por isto, mas por todos os desdobramentos estruturais e funcionais que demandam transformações no modelo de assistência em enfermagem e na saúde.

O surgimento das teorias de enfermagem revela, antes de mais nada, a tentativa de criação de um corpo de conhecimento que represente o trabalho realizado, 
no sentido de definir-lhe o objeto, os instrumentos e finalidades. Precisamos, então, discutir se o saber desenvolvido na enfermagem até agora dá conta de expressar o concreto da assistência. As teorias surgiram para responder a um desenvolvimento técnicocientifico geral e que acontece também no setor de enfermagem. para justificar a reivindicação de status e de autonomia dos enfermeiros. A enfermagem científica se propõe atć alterar o quadro geral de assistência à saúde.

Sem negar que é necessário buscar recursos teóricos que expliquem a prática. estes devem ultrapassar a dimensão do idcal para cxercer uma função de instnumentalizar aspectos da ação de enfermagem, da sua concepção à Sua realiıação, até à transformação das condições nas quais se concretiza. Se a tcoria não levar $\mathrm{cm}$ conta os processos que determinam tais condições, ela tende a ser apenas um modelo ideal. com base numa visr̃o idcalizada do mundo.

Para OREM', por exemplo, a enfermagem é agenciadora do auto-cuidado. nos déficits entre as necessidades c capacidades dos indivíduos para o auto-provimento das ações que sustentem a vida c a saúde. $\mathrm{O}$ objetivo do enfermeiro é climinar este déficit, logo que possível. através do ensino do auto-cuidado. Supõc que as pessoas sejam capazcs e queiram cuidar de si mesmas. porque têm responsabilidade sobre as escolhas que fa\%cm. Supõe que hajam possibilidades dc escolha. às quais o indivíduo adere $\mathrm{em}$ função de sua cultura c educação. $\mathrm{O}$ enfermeiro discutc tais responsabilidades e possibilidades, mas cxclusivamente ao nível do indivíduo e da situação presente.

A base é a teoria dos sistemas e do desenvolvimento humano. As necessidades dos clientes são vistas integradas aos sistemas interativos, nos quais cles estão incluídos ao longo da vida - escola, família, trabalho, cultura, religião, etc ... É uma tcoria funcionalista, pois busca a preservação e integralidade dos sistemas, e positivista ao querer explicar comportamentos que são tidos como de auto-cuidado numa dimensão de causa-cfeito, sem ir às raizes dos mesmos. É uma aproximação que reduz o ser humano a um conjunto de necessidades ou problemas. e que impõe ao enfermeiro a condução do processo de enfermagem. Do mesmo modo se apresentam os modelos de Abdella, Henderson, Horta, Beland e outras.

Já, um outro grupo de teoristas, tais como King, Travelbee, Orlando e Peplau, tende a ver enfermagem como um processo de interação inter-pessoal, com base no humanismo ético, existencialismo e fenomenologia. $\mathrm{O}$ enfermeiro é profissional $\mathrm{c}$ um ser humano que tem capacidades treinadas especificamente para ajudar em situações de doença, oú para manter a saúde. O cuidado é um ato humanista e o cliente é um parceiro, e a base são os valores do paciente, sua singularidade $\mathrm{c}$ dignidade.

Para $\mathrm{KING}^{2}$ a teoria de enfermagem é um marco de referência para a prática. A enfermagem é um processo de ação/reação/interação, no qual enfermeiro e cliente compartilham informações e traçam objetivos terapêuticos. A ação do enfermeiro ajuda a manter a saúde dos individuos para que possam "funcionar nos seus papéis", em sistemas pessoais, inter-pessoais e sociais, nos quais interage em busca de uma adaptabilidade que cause bem-estar, eliminando conflitos. Os elementos de análise são percepção, imagem, papel, organização, poder, autoridade, decisão e outros, congnuentes, com a maioria dos conceitos modernos da ciência ocidental, ou seja, humanismo, autonomia, auto-realização, valores pessoais, planejamento.

Um terceiro grupo de teoristas, tais como Rogers, Roy, Levine, Johnson, tenta enfrentar a questão da assistência de enfermagem dirigida para dois focos o imediato, no cuidado direto ao cliente, e o mediato, na intervenção sobre o meio.

ROGERS $S^{3}$ diz que a enfermagem é uma ciência que busca manter e promover uma relação entre o homem e o meio, de tal forma que fortaleça a integridade e coerência destes sistemas, entendendo-os como parte de um todo inseparável, em que a ruptura ou manutenção da organização num deles provoca desorganização ou continuidade do desenvolvimento no outro. Há, pois. um conjunto de inter-conexões entre os sistemas existentes. Saúde e doença são dimensões do processo vital e emergem destas interações. O mundo subjetivo deve ser avaliado segundo os padrões da ciência objetiva.

No entanto, o estudo da interação homem-meio restringe-se ao estudo da cultura, padrões de trocas energéticas, das necessidades de mudança. Não há a análise das determinações político-econômicas e sociais. Diz rejeitar o mecanicismo e o empirismo, pois entende que nem todos os eventos podem ser medidos e explicados. A idealização se evidencia quando ela diz que a realidade só existe como os homens a experimentam. Rogers não discute como é a prática destes conceitos, pois diz que o enfermeiro é um cientista que busca explicar e intervir sobre fenômeno que causem a doença.

Estas três teorias apresentadas representam sistemas de pensamento diferentes quanto ao foco de análise sobre o que é fazer enfermagem. Nenhum 
deles dirige o estudo da enfermagem e da saúde enquanto processos sociais, nem avalia as origens da situação da assistência de enfermagem, ou a quem c a que esta assistência se presta. Constroem um conhecimento em torno da realidade como se ela fosse restrita ao nível do indivíduo. $O$ objetivo da enfermagem é o bem-estar subjetivo, de acordo com as conotações e significados do paradigma da ciência positiva.

A $\mathrm{ABEn}^{4}$, enquanto entidade representativa, dos enfermeiros brasileiros, através da Comissão Permanente de Serviço, e o INAMPS, através de sua Coordenadoria de Enfermagem, apresentaram uma proposta de conceituação da assistência de enfermagem. No documento indicam que a assistência de enfermagem é parte da assistência integral à saúde e é dircito do cidadão.

Para a Comissão, que elaborou a proposta, a "assistência de enfermagem é aquela realizada por toda a categoria de Enfermagem, ou seja: enfermeiro. técnico, auxiliar de enfermagem, visitador sanitário $\mathrm{c}$ atendente". Além disto é um trabalho que é parte de um coletivo e contém um processo compartilhado por estas diferentes categorias que compõem um conjunto complementar e interdependente.

Todas estas propostas no sentido de conceituar assistência de enfermagem precisam ser avaliadas a partir da prática na busca de uma melhor aproximação com a teoria.

\section{ANÁLISE DA ASSISTÊNCIA DE ENFER- MAGEM EM RELAÇÃO À ASSISTÊNCIA À SAÚDE}

Se compreendida somente como uma visão que admite responsabilidade interna à Enfermagem sobre a situação da assistência à saúde, deixamos de ver as relações entre os dois planos c com o conjunto do processo social enquanto totalidade. Se, no entanto, significa desvendar o enfrentamento destas relações, então podemos tocar em alguns pontos cruciais da enfermagem.

A análise não será somente do pensamento dos indivíduos que prestam assistência, nem do conhecimento científico que têm da situação, mas também da sua prática que, sendo um momento no processo de produção, afeta de forma imediata o tipo de assistência e os interesses trabalhistas da categoria.

Afeta porque há conflitos e sua explicitação revela uma luta que não é dos indivíduos, cada um por si. com suas consciências, mas um processo coletivo que inclui desde a discussão do Sistema de Saúde e a qualidade da Assistência de Enfermagem, até as questõcs trabalhistas. A crise cxplicitada pode nos fazer avançar, desde que aprofundemos a análise das contradições, cscondidas e mascaradas $\mathrm{cm}$ scus conteúdos ideológicos, os quais aparecem, geralmente, como ciência, e por isto inquestionáveis porque supostamente neutros em relação a todo o sistema econômico-social.

O estudo da caracterização da assistência de enfermagem e sua influência na qualidade da assistência à saúde nos impõe algumas questões, que certamente não são as únicas $\mathrm{e}$ as últimas. e que apontam para dois níveis de problemas: $1^{\circ}$ ) o processo de trabalho da enfermagem, suas limitações e desenvolvimento: c $2^{\circ}$ ) os conflitos relativos à valorização deste trabalho, às possibilidades de autonomia profissional c à capacidade decisória do enfermciro no campo da saúde.

Parece que a tendência geral tem sido pensar que há dois modos de melhorar a assistência à saúde: melhores condições de trabalho, que incluem os instrumentos de trabalho, salário, organização estrutural e técnica c competência que inclue o estatuto de valorização no quadro geral das profíssões. Ambos representam o racional e o científico enquanto modos de pensar a mudança.

Esta tendência coloca o debate no campo do mercado de trabalho - e conseqüentemente no campo das lutas trabalhistas- pela valorização da força de trabalho da enfermagem. Se deslocarmos a discussão para a valorização do trabalho enquanto processo, estaremos deixando de ver o mercado como o cxclusivo campo do embate político e social, para incluí-lo em um outro plano mais amplo que é o das relações de trabalho, onde verdadeiramente se dão os conflitos.

De outro modo, o conflito aparece em sua superfície que é o da barganha entre a força de trabalho vendável-coisificada, transformada $\mathrm{em}$ mercadoria e o valor atribuído a esta mercadoria. Há duas conseqüências desta aparência; primeiro que o possuidor da força de trabalho, aqui o enfermeiro e os outros elementos da equipe de enfermagem, condicionado às leis do mercado, tende a adaptar-se às suas exigências e, segundo, a atividade realizada por esta força de trabalho aparece como algo independente do próprio trabalhador; ao concretizar-se, se torna imediatamentc uma abstração para ele, algo que afinal, não consegue apreender como resultado de sua ação. Perde o ser caráter de objetivação do que é exclusivamente humano, c por conscguinte, o seu carátcr histórico.

Já quando se olha para as relações de trabalho 
que o enfermeiro e os outros componentes da equipe de enfermagem estabelecem no sistema produtivo, aparece o trabalho em sua concretude, como um processo coletivo, que é parcializado, heterogêneo e hierarquizado. $\mathrm{E}$ aí aparece o conflito interno também, que é o da definição de papéis na divisão das tarefas em relação à suposta unidade ou integralidade do ato de prestar cuidados de enfermagem. E se aponta para o fato de que esta parcialização, determinada historicamente, e que destrói sua qualidade,se fez no e com o desenvolvimento das relações de trabalho no capitalismo, assimilando seus conteúdos ideológicos (morais, técnicos, finalísticos, etc...).

As entrevistas que realizamos possibilitaram captar a reflexão que os enfermeiros estão fazendo sobre estas questões, o que passaremos a apresentar e discutir a seguir.

\section{0 processo de trabalho da enfermagem, suas limitações e desenvolvimento}

\subsection{O que é o trabalho do enfermeiro?}

Através dos modelos teóricos propostos para realização do trabalho da enfermagem vimos que ele é percebido como uma atividade executada pelo enfermeiro junto ao cliente. A visão deste trabalho fica exclusivamente definida no plano da relação entre enfermeiro e cliente, e da metodologia indicada para apreender o objeto e interferir sobre ele. Não inclui as possibilidades concretas de realização deste trabalho em outros niveis, como o institucional, o comunitário e o político.

No entanto, os enfermeiros tem uma forma característica de definir seu trabalho, explicitando as funções que o acompanham, como as falas que se seguem:

- o enfermeiro faz um pouco de tudo; faz tudo pelo paciente; executa técnicas.

- o trabalho do enfemeiro não é só técnico, tem aspectos psico-sociais.

- é feito junto com outras categorias, mas há funções específicas do enfemeiro.

- é comandado pela rotina.

- é complementar ao do médico.

- o trabalho do enfermeiro é assistência direta, individualizado, com uso de recursos técnicos avançados, inclui o cuidado psicológico e deve ter continuidade.

Quando os enfermeiros falam sobre o seu traba- lho, mostram pelo menos duas tendências. De um lado, o trabalho é centrado no cliente, individualizado e especializado tecnicamente, de outro lado, é um trabalho coletivo, dividido com outras categorias, determinado pela instituição e que faz parte do processo de assistência à saúde.

Por conseqüência, estas questões relativas às condições e atributos do trabalho de enf ermagem, ou seja, parcialização, especialização, profissionalização, põem a nu a fragmentação do objeto de trabalho - o homem com seu corpo dividido e alienado de sua vida concreta - e do próprio trabalhador que não consegue mais dar conta da unidade orgânica entre o pensar e 0 fazer. Esta divisão, historicamente determinada, se expressa atualmente na enfermagem pela divisão do trabalho executado, em assistencial e administrativo. Os enfermeiros admitem csta divisão mas tendem a supor que somente poderão se sentir gratificados quando estão juntos do paciente, o que denominam assistência direta.

A apreensão do objeto de trabalho se faz a partir desta duplicidade, que faz parte do discurso e da prática dos enfermeiros. Quando questionados sobre este objeto, identificam como um trabalho mais próximo do paciente:

- é a assistência altamente especializada, técnicas mais complexas;

- para o enfermeiro com menos experiência é a assistência direta. Esta funciona como degrau para ser capaz de administrar;

- o enfermeiro assiste o paciente mais grave;

- fazer visitas domiciliares, estar em contato com a comunidade;

- educação em saúde.

Mais ligado à organização do serviço, apontam:

- racionalização e planejamento para instituição, coordenação da equipe;

- organização de programas, rotinas, escala de funcionários, treinamentos de pessoal, distribuição de tarefas inclusive no trabalho médico;

- controle e coordenação de vários setores (lavanderia, farmácia, serviço médico, refeitório, etc...).

Alguns enfermeiros conseguem expressar uma visão em que sintetizam estes dois aspectos acima referidos:

- a administração significa decisões sobre os cuidados, por isto estão mais na administração;

- o papel do enfermeiro não é dicotomizado, ele tem 
que aprofundar conhecimentos e trabalhar pela questão geral da saúde;

- a dif erença entre administração e assistência direta é um modo de falar.

Analisando, podemos observar, quando os enfermeiros expressam sua posição acerca do trabalho que realizam, uma ênfase em sentimento de culpa quando fazem mais administração do que o cuidado direto. Dizem que a rotina se impões e quando exercem a chefia precisam assumir posturas autoritárias. Há uma busca de autonomia e valorização do trabalho do enfermeiro, tanto no aperfeiçoamento técnico e científico do cuidado, quanto na administração competente. Isto remete à idéia de especializações como forma de valorização.

Em relação a estas questões os enfermeiros têm posições idealistas, humanistas, racionalizadoras.. É idealista quando ele não questiona as limitações e os determinantes institucionais, e busca autonomia, através da competência e especializações para valorizar o trabalho:

- depende do enfermeiro ir à luta pelo seu espaço:

- é preciso muito trabalho para mudar a situação do enfermeiro;

- o enfermeiro não está fazendo assistência direta por uma escolha pessoal;

- há um trabalho específico da assistência e de administração que deve ser feito pessoas diferentes;

- o enfermeiro faz uma assistência mais segura e competente porque sabe mais.

É humanista quando coloca ênfase nas relações com a clientela:

- fazer enfermagem é estar junto da cabeceira do paciente;

- o trabalho do enfermeiro deveria ser educativo, pois isto garante a independência e valorização.

É racionalizador quando exprime tendências de delimitar funções, normas:

- deveria haver dois tipos de enfermeiros especializados, os de cuidado e os de supervisão;

- seria bom que houvesse um trabalho específico e autônomo para o enfermeiro.

Tanto a "tradição" idealizada de "retorno" do enfermeiro ao cuidado direto do paciente, enquanto proposta unificadora para a enfermagem, quanto a busca de um ideal científico de competência prestada aparecem tão somente como maneiras de engajamen- to à necessidades formais de adaptação as desenvolvimento do capitalismo no setor saúde.

Neste sentido, reproduzindo os modelos "científicos" estruturais e vigentes, manifesta-se também na enfermagem o seu traço mais marcante que é a perda da noção de totalidade do objeto de trabalho, e do próprio processo de intervenção sobre este objeto. E as especialidades médicas tendem a se repetir como especialidades de enfermagem.

A especialização é conseqüência da divisão técnica do trabalho, contigencial e necessariamente de acordo com o desenvolvimento das relações de produção que dele decorrem. Não é pois necessidade interna da enfermagem em si, mas aparece como tal no discurso da busca de autonomia e "status" científico. Sob este ângulo, o trabalho de enfermagem se fragmenta duplamente. Em primeiro lugar, porque há diferentes trabalhadores que o executam numa escala hierarquizada segundo a apropriação do saber, e em segundo lugar, porque se propõe a interferir sobre o objeto de forma parcial. Na medida em que a ciência e a tecnologia não podem ser negadas, se busca na especialização esta competência. Ao enfrentar esta questão da competência, podemos observar que ela pode ser compreendida sob dois pontos de vista: 1) competência significando conhecimento, habilidade, qualidade real da assistência e 2) competência através do formal: ordem, disciplina, hierarquia que levam à aparente produtividade e que servem aos objetivos institucionais. A primeira é capaz de transformações porque amplia o trabalho para além do técnico e vai à discussão do político, e neste sentido incomoda, porque o processo é remetido para o coletivo. A segunda, ao contrário não transforma, somente nomatiza.

Há ainda um discurso aparentemente politizado mas que tem apenas uma conotação de oposição ao poder. É alienado porque dissocia a reflexão da ação competente, o que se expressa como uma espécie de contra-competência.

Pelo caminho da busca da competência, o ensino da enfermagem tenta estabelecer um estatuto de cientificidade para as ações de enfermagem, através de teorias e modelos de assistência, para realizar o objetivo da qualificação e da autonomia profissional, porém já vimos que na prática o estatuto é normativo, na direção da organização, racionalização e divisão de tarefas. Daí a inconsistência entre o saber e a prática neste momento da história da enfermagem. Se o critério de verificabilidade científica das proposta teóricas da enfermagem for a sua aplicação prática, então se poderia dizer, no mínimo, que a produção de co- 
nhecimento nesta área não tem correspondido a uma aproximação concreta com a realidade porque não está modificando a prática. Embora continue a ser uma forma de ver a realidade, sem dar conta de explicitar todas as contradições desta realidade. A apreensão do real não se traduz meramente no conceito ou idéia que se faz do real, mas na sua possibilidade de transformar-se com a transformação da realidade mesma e de desvendar as formas como são possíveis estas transformações. Assim, as teorias e interpretações sobre a realidade têm de ser vistas na sua limitação histórica, comodiz GRAMSCI ${ }^{5}$. Precisamos olhar oqueestá acontecendo na história social e econômica, diz ele, para termos a chave para compreender as transformações no conhecimento e na prática. Não como forma de apenas iluminar o que está obscuro, porque isto significa colocar o intelectual acima e à parte daquilo que estuda. Não se trata, diz $\mathrm{LOWY}^{6}$, de esperar que um indivíduo "sábio"ou um grupo de sábios transformem, mas de um pensar coletivo que busca simultaneamente mudar as condições estruturais, a sociedade e os próprios indivíduos.

\subsection{Divisão do trabalho na enfermagem e os vários agentes}

A enfermagem enquanto forma de conhecimento, tem se articulado com todo o desenvolvimento do conceito de saúde/doença e do campo hospitalar, com seu aparato técnico-burocrático. A medicina abre-se aos recursos of erecidos pela indústria moderna e estabelece-se, como se pode ver hoje, entre ela e a sociedade, uma articulação que escapa das esferas da patologia e da conduta terapêutica em si. A função social do médico se explicita e indica um processo de vinculação com a economia capitalista cada vez mais estreito. "A moderna medicina tecnológica representa, antes de tudo, a mediação de um conjunto enorme de novos recursos de diagnóstico e terapêutica na relação entre o médico e o objeto de seu trabalho. (...) realizando através de seu consumo na prática médica, a mais-valia produzida em outros setores, os novos meios de trabalho instauram um vínculo direto e específico entre a medicina e os objetivos básicos da produção econômica"7. E isto acontece também com a enfermagem, uma vez que usa os equipamentos, procedimentos terapêuticos e o mesmo espaço de trabalho que a medicina, embora em seu âmbito específico, que não deixa de ser complementar àquele.

$\mathrm{O}$ ato de assistir se modificou ao longo do tempo e a enfermagem passa por uma reorganização intema de modo que aparece um profissional que além de deter um conhecimento amplo sobre o campo da biologia humana ainda começa a assumir papéis impostos pela nova estrutura organizacional do hospital e outras instituições de saúde. Assistir inclui, então, o gerenciamento do meio hospitalar e a coordenação de um trabalho que se divide não só por especialidades, mas por complexidade. Tarefas simples, medianas e complexas da assistência passam a ser distribuídas por diferentes elementos de uma equipe. $\mathrm{O}$ "assistir" se torna um trabalho coletivo.

Deste modo, a questão da competência profissional não se resume à sua explicitação enquanto aprimoramento técnico, ou da volta do enfermeiro ao pé do leito, mas passa pela reflexão das suas implicações no plano das transformações ou conservações do modelo de assistência instituído..

O que podemos fazer, neste momento é buscar refletir sobre como se dá esta divisão do trabalho na enfermagem na visão dos enfermeiros entrevistados:

- não há limites definidos na divisão de tarefas, elas se distribuem de acordo com habilidades pessoais;

- trabalhar em equipe é trabalhar junto.

O enfermeiro que "trabalha junto" é aquele que não se nega a fazer trabalhos manuais, passa para a equipe a imagem de ser bom, competente, legitimando sua autoridade sobre a equipe.

- há limites de competência e de salário que impõem uma divisão de trabalho sem critérios: há categorias que tem menos responsabilidades e que ganham mais;

- o enfermeiro não faz o cuidado direto mas sabe tomar decisões no planejamento da assistência; é responsável pelo treinamento dos funcionários e distribui as tarefas de acordo com a capacidade do pessoal que tem.

Na visão de alguns, a organização da assistência pode ser realizada pela vontade do enfermeiro, sem passar pela discussão em equipe: não percebem a divisão do trabalho. Para outros a divisão é real, tem que existir sem que o enfermeiro assuma uma postura autoritária. Se o enf ermeiro proporcionar um relacionamento humano na equipe e entre a equipe e a clientela ele pode contribuir para melhorar a qualidade da assistência. Há enfermeiros, ainda, que embora assumam a organização e planejamento, delegam não só atividades de assistência, como também tarefas burocráticas.

O enfermeiro sempre sentiu a necessidade de trabalhar com pessoal auxiliar capacitado, criando os cursos de auxiliar e de visitador sanitário. Esta capa- 
citação, porém veio cheia de contradições, pois delega funções que lhe são específicas e para compensar cria uma relação de dominação sobre estes auxiliares. Daí a dificuldade de encaminhar o projeto de profissionalização do atendente.

As categorias que exercem a enfermagem pertencem a classes sociais diferentes, portanto, têm concepções diferentes sobre as transformações necessárias, e isto se dá porque há questões ideológicas, supra-estruturais, que não permitem a universalização das tendências, implicando em formas diferenciadas nas lutas trabalhistas. Este conflito não deve ser negado mas enfrentado, propiciando caminhos para a mudança.

Apesar da divisão que se realiza entre os diversos agentes, socialmente aparece um mesmo e único trabalho - assistência de enfermagem, que conceitualmente deve ser feito de forma unitária. Parece que os componentes da equipe de enfermagem produzem algo único e universal. A diferença fica por conta de atributos pessoais e não de condições concretas num modo de planejar e executar o trabalho determinado socialmente.

\subsection{Finalidade do trabalho de enfermagem}

Nas entrevistas, quando questionados sobre a finalidade do seu trabalho, os enfermeiros enfatizam três pontos:

- prestar assistência ao indivíduo e à família visando melhorar a sua saúde;

- proporcionar a infra-estrutura para o atendimento à saúde, acionar o funcionamento das unidades exercendo o controle das atividades, fazer o trabalho do médico dar certo;

- ensinar em todos os sentidos a população a pensar sobre as condições de vida e saúde, conscientizar.

Eles têm uma resposta universal e abstrata para a finalidade do seu trabalho. Entretanto, algumas falas diversificam esta finalidade de acordo com a visão que têm do setor saúde:

- a distribuição dos atendimentos é diferenciada nos extratos sociais;

- o enfermeiro que trabalho na medicina de grupo é mais qualificado que o do INAMPS;

- o enf ermeiro não tem espaço para opinar no setor saúde, as mudanças são impostas até para o médico;

- o hospital particular of erece melhores condições de assistência.

Conforme verificamos percebem que a finalidade do seu trabalho está determinada, em primeira instância, pela organização do setor de saúde, e em segunda, pela instituição.

Um conflito que se apresenta para os enfermeiros é deparar-se com o fato de que embora eles aprendam que todos os indivíduos têm direito a uma assistência adequada às suas necessidades, 0 sistema de saúde via diferentes instituições distribui os pacientes de acordo com a classe social a que pertencem, porque tem finalidades que são anteriores à clientela. Ou seja, esta clientela já é determinada por estas finalidades, e temos então "paciente particular", "paciente INAMPS", "paciente indigente", etc... Isto implica que, Hospital de Ensino, Posto de Saúde, Hospital conveniado, Hospital particular definem antecipadamente por suas diferentes finalidades, os pacientes que o procuram e o tipo de assistência oferecida. Não depende, pois, exclusivamente do enfermeiro estabelecer o caráter de trabalho, porque há outras determinações que entram nesta definição.

\section{Limitações para a realização do trabalho de enfermagem}

No momento em que o enfermeiro exlplicita o que é o seu trabalho, como ele o executa e qual a sua finalidade, aparecem as limitações:

competição entre colegas pela competência;

- hierarquia rígida e centralização do poder na chefia de enfermagem, avaliação em termos de punições;

- dificuldade de se impor por ser mulher;

- salários baixos;

- os médicos não sabem o que os enfermeiros fazem;

- problemas de comunicação entre os profissionais e falta de respeito entre os mesmos;

- excesso de trabalho; rotatividade do trabalho;

- insatisfação por causa das funções administrativas;

- falta de material e espaço;

- a instituição não permite que ele desenvolva seu potencial, não propicia educação continuada;

- desarticulação política do setor saúde;

- dificuldade em lidar com outros níveis de poder (a nivel estatal);

- não poder fazer a ligação entre o cuidado direto e os aspectos burocráticos do mesmo, tais como, 
controle de estoques. dados cstatísticos c outros:

Diantc de uma formação tcórico-conccitual c de uma prática concreta que não correspondc a cla. o enfermeiro identifica as limitações c não conscguc transpô-las. Além disto há contradições inerentes ao próprio sistema de saúdc. Alguns se accrcam destas questõcs c outros as negam ou as colocam fora ou acima de sua responsabilidade

Na percepção sobre o clientc. de um modo geral. o cnfermciro não entende o dircito à saúde cnquanto dircito de cidadania. No INAMPS $\mathrm{c} \mathrm{cm}$ outras instituições estatais. o cliente obedece porque ć ignorantc c precisa aprender. nas instituições privadas. porque paga. cle $\mathrm{tcm}$ dircito a cxigir.

Alguns enfermeiros acreditam que o clicnte perccbe o trabalho diferenciado do enfermciro na cquipe de enfermagem c o respeita porque cle fay coisas específicas, tarefas só delc. c porque resolve os scus problemas. Outros, informam quc o paciente não percebc a diferença do trabalho do enfermciro. qucixamse da assistência c o identificam com o hospital.

Há uma relação entrc cstas infommaçõcs c a organização das instituiçõcs detcrminada pelo scu caráter privado ou cstatal. Os enfermciros cxplicitam cstas relaçõcs da scguinte forma:

- o sctor saúde tem propostas boas. mas na prática clas não estão claras, há interesses conflitantes:

- a reformulação do sctor saúde beneficiou os clien- tes (maior atcndimento da demanda), mas não bcneficiou os servidores $\mathrm{cm}$ relação às condições de trabalho

- há interferências políticas no andamento c continuidade do trabalho:

- há relações cntrc o trabalho do enfermciro c as condições do sctor saúde:

- não basta criar unidades básicas na periferia c dcixálas isoladas. É preciso integrá-las através de diversos mecanismos administrativ os c de cducação continuada:

- com a implantação do SUDS, as unidades básicas. dependentes do Estado c do Município, têm dificuldades nas decisões. não houve realmente a descentralização normativa c cxccutiva.

Evidentemente todas as dificuldades apontadas pelos enfermeiros estão ligadas ao processo de $\mathrm{c} d \mathrm{~d}$ senvolvimento do sctor saúde nas condições cconômicas e políticas da socicdadc. A normatização sobre o atendimento à saúde impõc ao $\mathrm{c}$ nferneciro condiçõcs para a realiz ação do scu trabalho, que cle nem sempre comprecnde ou accita. porque nào $\mathrm{vem}$ lomando decisõcs ncsic processo

A assistência de enfermagem. por todas as determinaçõcs por que passa. não sc apresenta lıomogênca. unitária c igual para todos os scus clicntes. É diferenciada. parcclada.

\section{CONSIDERAÇÕES FINAIS}

Através dos dados empíricos levantados. verificamos que não sc pode fazcr uma caractcrização da assistência de cnfernagem, no momento atual. como se esta fossc universal e homogênea.

Mcsmo tendo sido caracterizada a assistência de enfermagem no município de Ribcirão Preto, csta mostrou-sc bastante diversificada. Deve-se à diferenciação das instituiçõcs. enquanto cstatais privadas, ao nível de complexidade de atendimento. que vai de unidades básicas a hospitais gerais c especializados $\mathrm{c}$ às especialidades clínicas onde alguns enfermeiros atuam

Podemos concluir da análise fcita que o trabalho do enfermeiro passa atualmentc por um processo dc transição que sc obsen a pela identificação de vários objetos de trabalho, a comprecnsão do que scja sua compctência. a divisão do trabalho. os vários agentes. a finalidade do mesmo $\mathrm{c}$ as limitaçõcs para a sua rcalização.

Assim alguns enfermeiros restringem a sua atuação uma visão interna técnica c imcdiata do scu trabalho. desconhecendo até as interferências da própria instituição c a necessidade da articulação com o sctor saúdc como um todo. Outros já ampliaram o scu papcl c se posicionam, não apcnas enquanto um profissional técnico. mas como agentes políticos possibilitando transformaçõcs.

Obscriamos que o trabalho do cnfermeiro se direciona para duas tendências, ou scja. a função administrativa, que possibilita a coordenação da assistência de cnfermagem na unidade e na instituição onde se dá a assistência, assim como permite participar de níveis decisórios do setor saúde. A segunda tendência ć a especialização para atender o alto nível de complexidade das unidades do sctor secundário c terciário.

Gostariamos aqui de salientar a importância do papel administrativo na assistência de cnfermagem, e que foi muito cvidenciado na fala dos enfermciros, mas não como o pólo oposto do cuidado (pelo contrário, agregado a cstc cuidado) $\mathrm{c}$ ncm como uma atividade tomada como se não fossc objeto do enfermeiro. 
Parece-nos sim que o trabalho administrativo do enfermeiro deva ser resgatado no que diz respeito ao aprofundamento científico do processo administrativo agregado à competência técnica da assistência. Este tem sido concretamente o encaminhamento histórico que está tomando o trabalho do enfermeiro.
A caracterização daassistênciade enf ermagembuscando suas limitações e conflitos permite conhecer 0 processo de trabalho e ajuda a direcioná-lo na melhoria da qualidade da assistência de enfermagem.

\section{REFERÊNCIAS BIBLIOGRÁFICAS}

1 OREM, Dorothea - Nursing. Concept of practice. Ed. Mc Graw-Hill, N.Y. U.S.A., 1980.

2 KING, Imogene - Toward a theoryfor nursing. Ed. John Wiley \& Sons, N.Y, U.S.A, 1971.

3 ROGERS, Martha E. - An introduction to the theoretical basis of nursing. Ed. F.A. Davis, Philadelphia, 1970.

4 ASSOCIAÇÃO BRASILEIRA DE ENFERMAGEM INAMPS - Subsidios para a conceituação da Assistência de Enfermagem rumo a Reforma Sanitária. REBEn, 40 (2/3), 1987, p.177-80.
5 GRAMSCI, Antônio - Os intelectuais e a organização da cultura, Ed. Civilização Brasileira, R.J, 1988, $6^{2}$ ed.

6 LOWY, Michael - Ideologia e ciência social-elementos para uma análise marxista, Ed. Cortez, S.P. 1988, $4^{2}$ ed.

7 DONNANGELO, M.C.F. - Medicina e Sociedade, Ed. Duas Cidades, SP. 1979. $2^{2}$ ed. 